\title{
Seleção de progênies de nabo-forrageiro para germinação sob altas temperaturas
}

\author{
Selection of progenies of wild radish germination under high temperatures
}

\author{
Silvia Sanielle Costa de Oliveira ${ }^{\mathrm{I}}$ Cibele Chalita Martins ${ }^{\mathrm{II}}$ Sihélio Júlio Silva Cruz \\ Carlos Jorge da Silva ${ }^{\text {III }}$
}

\section{RESUMO}

Devido à expansão da cultura do nabo-forrageiro para regiões com temperaturas mais elevadas, torna-se de importância o desenvolvimento de cultivares adaptadas a altas temperaturas. Neste trabalho, o objetivo foi selecionar testes de avaliação da qualidade fisiológica de sementes nabo-forrageiro que estimam caracteres genéticos, visando a selecionar genótipos adaptados a condições de alta temperatura. Para isso, sementes de 100 progênies de meio-irmãos de nabo-forrageiro foram submetidas a teste de germinação e vigor (primeira contagem de germinação, classificação do vigor de plântulas, teste de envelhecimento acelerado, germinação e teste da primeira contagem a altas temperaturas), bem como emergência de plântulas em campo. O teste de primeira contagem, germinação, envelhecimento acelerado, primeira contagem e germinação em alta temperatura $\left(20-35^{\circ} \mathrm{C}\right)$ são recomendados para delinear estratégias de seleção de populações de nabo-forrageiro adaptados à germinação e emergência de plântulas em campo, em condições de altas temperaturas.

Palavras-chave: ganho genético, herdabilidade, Raphanus sativus, sementes, vigor.

\section{ABSTRACT}

Due to the expansion of the wild crop to regions with higher temperatures is important to develop cultivars adapted to high heat. The aim was to select tests for evaluating seed physiological quality of wild radish to estimating genetic characters in order to select cultivars adapted to high temperature conditions. Hundred of half-brothers of wild radish were subjected to germination test and vigor (first count of germination, classification of seedling vigor, accelerated aging test, germination and testing of the first count at high temperature as well as seedling emergence in field. The germination test, first count test, accelerated aging and high germination test $\left(20-35^{\circ} \mathrm{C}\right)$ can be used for the selection of wild radish crop populations adapted to germination and field emergence under high temperatures.

Key words: genetic gain, heritability, Raphanus sativus, seeds, vigor.

\section{INTRODUÇÃO}

O nabo-forrageiro (Raphanus sativus L. var. oleiferus Metzg.), originário do Sul da Europa e cultivado principalmente na Ásia Oriental e Europa, está entre as mais antigas espécies utilizadas para a produção de óleo (DERPSCH \& CALEGARI, 1992). No Brasil, essa planta tem sido cultivada nas regiões Sul, Sudeste e Centro-Oeste como adubo verde e planta de cobertura em sistemas de cultivos conservacionistas, a exemplo do plantio direto (CRUSCIOL et al., 2005), e vem se expandindo para regiões em que predominam altas temperaturas. No município de Jataí (Goiás), a cultura do naboforrageiro foi promissora na produção de biomassa para cobertura de solo (SOUZA et al., 2008); em Montes Claros no Norte de Minas Gerais, o cultivo dessa espécie como adubo verde proporcionou incrementos na produtividade da cultura sucessora (VALADARES et al., 2012).

Em ambas as regiões citadas acima, durante o inverno, podem ocorrer temperaturas

\footnotetext{
'Universidade Federal de Goiás (UFG), Campus Jataí, Unidade Jatobá, Jataí, GO, Brasil.

"Departamento de Produção Vegetal, Faculdade de Ciências Agrárias e Veterinárias (FCAV), Universidade Estadual Paulista (UNESP), 14884-900, Jaboticabal, SP, Brasil. E-mail: cibele@fcav.unesp.br. Autor para correspondência.

IIIPrograma de Pós-graduação em Agricultura, Departamento de Produção Vegetal, UNESP, Botucatu, SP, Brasil
}

$$
\text { Recebido 26.11.12 Aprovado 29.08.13 Devolvido pelo autor 30.11.13 }
$$


acima de $30^{\circ} \mathrm{C}$, assim, a garantia de sucesso na produção de massa seca (plantio direto) ou verde (adubação verde), dependerá, dentre outros aspectos, do estabelecimento das plântulas no campo, o que, segundo CARVALHO \& NAKAGAWA (2012), está diretamente relacionado com a germinação e vigor das sementes. Na escolha de espécies para o sistema de plantio direto, é importante definir uma cultura para a formação da cobertura adaptada às condições climáticas da região (SOUZA et al., 2008).

De acordo com a RAS - Regras para Análise de Sementes - (BRASIL, 2009), a temperatura ideal para a germinação de sementes de nabo-forrageiro é de $20^{\circ} \mathrm{C}$ constante. No entanto, NERY et al. (2009a) identificou que o regime de temperatura ideal seria de $20-30^{\circ} \mathrm{C}$ para as principais cultivares disponíveis no mercado ('CATI AL-1000' e 'IPR 116'), permitindo comprovar a existência de tolerância de algumas populações dessa forrageira de inverno à temperaturas mais elevadas de germinação do que aquela recomendada pelas RAS. Para garantir a expansão da cultura para as regiões Nordeste e Centro-Oeste do Brasil, será necessária a seleção de cultivares com maior capacidade de germinação em condições de temperaturas mais elevadas.

A variabilidade genética é uma característica importante para o trabalho de melhoramento de plantas, pois facilita a obtenção de materiais adaptados e produtivos às diversas condições edafoclimáticas. Entre os testes de avaliação da qualidade das sementes realizados em laboratórios, os de germinação, primeira contagem e envelhecimento acelerado, podem ser utilizados em programas de melhoramento genético para a comparação e posterior seleção de linhagens e cultivares com sementes de qualidade superior (VIEIRA et al., 2005; MARTINS et al., 2012).

A estratégia de melhoramento genético, utilizada para a seleção de linhagens de soja visando à qualidade da semente e adaptação a ambientes tropicais com altas temperaturas, foi baseada principalmente no teste de envelhecimento acelerado (KRZYZANOWSKI, 1998). Esse teste baseia-se no aumento da deterioração das sementes expostas a condições adversas de alta temperatura e umidade relativa, pois, nessas condições, sementes de baixa qualidade deterioram-se mais rapidamente do que aquelas mais vigorosas, estabelecendo diferenças no potencial fisiológico das amostras avaliadas (MARCOS FILHO, 1999). Para selecionar populações de cenoura, adaptadas à germinação em altas temperaturas, os teste de germinação e primeira contagem conduzidos sobre papel a 20 e $35^{\circ} \mathrm{C}$ foram eficientes (SILVA et al., 2011).
Dessa forma, esta pesquisa objetivou selecionar testes de avaliação da qualidade fisiológica de sementes nabo-forrageiro que estimem caracteres genéticos, visando a selecionar genótipos adaptados à condições de alta temperatura.

\section{MATERIAL E MÉTODOS}

As populações avaliadas foram 100 meio-irmãos oriundos de uma população de naboforrageiro, cultivar 'AL1000', pertencentes ao programa de melhoramento para produção de óleo do Departamento de Produção Vegetal da Faculdade de Ciências Agronômicas da UNESP - Campus de Botucatu, SP. As progênies foram obtidas a partir da coleta manual e mistura das sementes de todas as síliquas de plantas individuais depois da secagem. Após a limpeza manual, as sementes foram submetidas às seguintes determinações e testes:

Determinação do grau de umidade - foi realizada antes da instalação dos testes e após o teste de envelhecimento acelerado, utilizando-se duas subamostras de sementes com sete gramas cada, pelo método da estufa a $105 \pm 3^{\circ} \mathrm{C}$, por 24 horas (BRASIL, 2009); teste de germinação - foi realizado com quatro subamostras de 50 sementes, semeadas sobre duas folhas de papel, umedecido com água destilada na quantidade equivalente a 2,5 vezes o peso do papel seco e colocadas em caixas plásticas transparentes $(11,0 \times 11,0 \times 3,5 \mathrm{~cm})$, incubadas em BOD (Biochemical Oxigen Demand). Esse teste foi regulado à temperatura de $20^{\circ} \mathrm{C}$, cujas contagens de plântulas normais foram efetuadas no quarto dia e $10^{\circ}$ dia após a instalação do teste (BRASIL, 2009); primeira contagem de germinação - foi realizada conjuntamente com o teste de germinação, contabilizando-se as plântulas normais presentes no quarto dia após a semeadura (BRASIL, 2009); classificação do vigor de plântulas - na data correspondente à primeira contagem do teste de germinação, as plântulas normais bem desenvolvidas foram retiradas, computadas e classificadas como "fortes" (vigorosas), enquanto, no período correspondente à contagem final, as plântulas remanescentes foram avaliadas como normais ou anormais, sendo as normais classificadas como "fortes" ou "fracas". As plântulas normais "fracas" foram consideradas como aquelas com algum problema em sua estrutura ou lesão, mas insuficientes para caracterizá-las como anormais (NAKAGAWA, 1999); teste de envelhecimento acelerado tradicional - foi conduzido com quatro gramas de sementes dispostas sobre tela em caixas plásticas do tipo gerbox, contendo $40 \mathrm{~mL}$ de água destilada (100\% UR) em cada uma e 
mantidas a $41^{\circ} \mathrm{C}$ por 96 horas (NERY et al., 2009b), seguido do procedimento do teste de germinação com avaliação da porcentagem de plântulas normais no quarto dia após a semeadura; germinação em altas temperaturas - foi utilizada a mesma metodologia descrita para o teste de germinação, porém conduzido em BOD nas condições de temperaturas alternadas de $20-35^{\circ} \mathrm{C}$ e $25-40^{\circ} \mathrm{C}$ e fotoperíodo de 8 horas de luz na temperatura mais elevada; primeira contagem de germinação em altas temperaturas - foi realizada conjuntamente com o teste de germinação em altas temperaturas, contabilizando-se as plântulas normais presentes no quarto dia após a semeadura; teste de emergência de plântulas em campo na estação da primavera - conduzido em canteiros no campo e a semeadura realizada na segunda quinzena de outubro de 2012, em Jaboticabal, SP. As parcelas foram constituídas por dois sulcos de $1,5 \mathrm{~m}$, espaçados de $0,2 \mathrm{~m}$, semeando-se 50 sementes por sulco à profundidade de 2 a $3 \mathrm{~cm}$, sendo as contagens realizadas diariamente até os 12 dias após a semeadura, sabendo que as temperaturas mínimas e máximas médias diárias vigentes no período do teste foram de 22 e $37^{\circ} \mathrm{C}$, respectivamente. Este controle foi realizado com o auxílio de um termômetro, instalado próximo aos canteiros, que registrou a temperatura máxima e mínima diária; a irrigação foi diária, visando a manter a umidade do solo em nível adequado.

Os dados obtidos foram redistribuídos nos moldes adequados para a análise estatística no aplicativo Genes-UFV (CRUZ, 2001), submetidos à análise de variância, covariância e estimados os seguintes parâmetros: variância fenotípica entre médias de progênies $\hat{\sigma}_{f}^{2}=(Q M P / r)$; variância genotípica entre médias de progênies $\hat{\sigma}_{g}^{2}=(Q M P /$ $Q M R) / r$; variância ambiental média $\hat{\sigma}^{2}(Q M R / r)$; herdabilidade no sentido amplo, baseada na média das parcelas $h^{2}=\hat{\boldsymbol{\sigma}}_{g}^{2} / \hat{\mathbf{\sigma}}_{f}^{2}$; coeficiente de variação genética $\sqrt{\hat{\sigma}_{g x}^{2} \cdot \hat{\sigma}_{z y}^{2}}$, o qual corresponde à média geral do caráter. Correlações ambientais $r_{a}=P M R_{x y} / Q M R_{x} \cdot Q M R_{y}$; correlações genéticas $r_{g}=\mathrm{s}_{g x y} / \sqrt{\hat{\sigma}_{\varepsilon r}^{2} \cdot \hat{\sigma}_{\varepsilon r}^{2}} ;$ ganho por seleção $G S=D s \cdot h^{2}$, sendo $D s=Y_{s}-Y_{o}$, em que $D s$ corresponde ao diferencial de seleção entre famílias; $\mathrm{Y}_{\mathrm{s}}$ a média das famílias selecionadas e $\mathrm{Y}_{\mathrm{o}}$ a média da população base.

\section{RESULTADOS E DISCUSSÃO}

O grau de umidade inicial das sementes das progênies de nabo-forrageiro foi de 4,5 $\pm 1,5 \%$. Essa semelhança de valores é primordial para que os testes não sejam afetados por diferenças na atividade metabólica, velocidade de umedecimento e na intensidade de deterioração das sementes. Recomenda-se que não haja diferenças superiores a $2 \%$ de teor de água das sementes das amostras antes do envelhecimento (MARCOS FILHO, 2005).

Após o teste de envelhecimento acelerado, o grau de umidade das sementes situou-se entre 28 e $47 \%$; portanto, apresentou-se relativamente desuniforme entre as progênies e com variações de até $19 \%$. Apesar das variações entre o grau de umidade determinadas após o envelhecimento serem superiores a $3-4 \%$, que são considerados toleráveis entre lotes (MARCOS FILHO, 1999), deve-se enfatizar que, nesta pesquisa, as comparações foram entre sementes de progênies (geneticamente diferentes) e não entre lotes (geneticamente iguais). As diferenças elevadas no grau de umidade entre sementes de diferentes progênies após o envelhecimento acelerado também foram relatadas em cenoura (MARTINS et al., 2012), pois algumas características que diferem entre sementes de diferentes genótipos podem influenciar na absorção de água, como, por exemplo, tamanho da sementes, a permeabilidade do tegumento e a composição química (CARVALHO \& NAKAGAWA, 2012).

No presente estudo, parte das diferenças genéticas entre as sementes das progênies de naboforrageiro é devida a divergências no teor de óleo delas. Isso se dá visto tratar-se de uma espécie oleaginosa, cujos ciclos anteriores de seleção visavam ao aumento no teor de óleo, o qual está diretamente relacionado com o grau de umidade de equilíbrio (CARVALHO \& NAKAGAWA, 2012).

Nas populações de nabo-forrageiro, constataram-se diferenças significativas para todas as características (Tabela 1), com altos valores do coeficiente de variação genética entre progênies para os testes em estudo, sugerindo que há possibilidade de ganhos expressivos durante a seleção para todos os caracteres avaliados. Esses caracteres estão relacionados com a qualidade das sementes, como germinação e vigor, principalmente em condições de altas temperaturas no teste de germinação e emergência de plântulas nas condições de altas temperaturas de campo.

As estimativas dos caracteres genéticos de herdabilidade e da relação entre os coeficientes de variação genética e experimental refletem uma situação favorável à seleção, pois variaram entre 67 a $91 \%$ para a herdabilidade e, 0,72 a 1,63 para a relação entre os coeficientes de variação genética e experimental (Tabela 1). Quando a relação entre 
Tabela 1 - Análise de variância e estimativa dos caracteres genéticos para os testes de avaliação ${ }^{1}$ de sementes de 100 progênies de meioirmãos de nabo-forrageiro. Botucatu - SP, 2012.

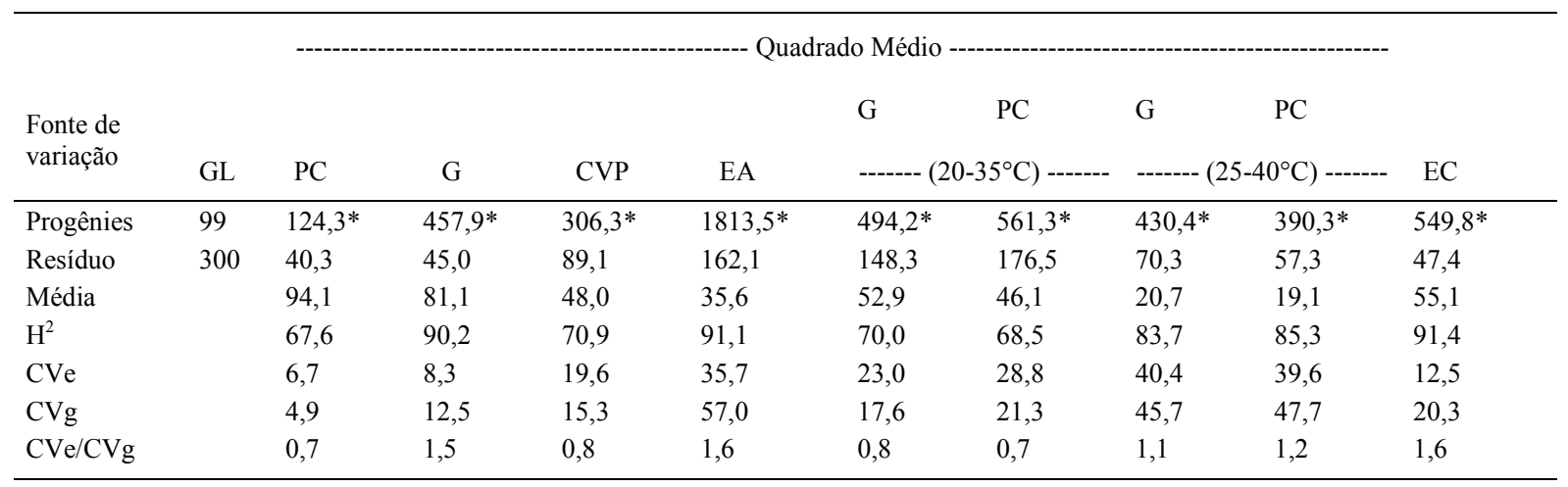

${ }^{1}$ Teste da primeira contagem (PC), germinação (G), classificação do vigor de plântulas (CVP), envelhecimento acelerado (EA), germinação e teste de primeira contagem em altas temperaturas $\left(20-35\right.$ e $\left.25-40^{\circ} \mathrm{C}\right)$ e emergência de plântulas na primavera (EC).

*Significativo em nível de $1 \%$ de probabilidade pelo teste $\mathrm{F} ; \mathrm{H}^{2}$ herdabilidade (\%); CVe - coeficiente de variação experimental; CVg coeficiente de variação genética.

os coeficientes de variação genética e experimental tende ou é maior que 1,0, a variação genética supera a ambiental VENCOVSKY \& BARRIGA (1992). Por esse princípio, a seleção, quando é praticada no primeiro ano, maximiza o ganho genético, que vai diminuindo a partir dos anos subsequentes. $\mathrm{O}$ maior valor da relação $\mathrm{CVg} / \mathrm{CVe}(1,63)$ foi observado para emergência em campo, em condições de altas temperaturas (na primavera), indicando que a seleção, em termos de ganhos genéticos imediatos, é mais favorável, embora valores bastante promissores tenham sido observados para germinação $(1,51)$, vigor, avaliado pelo teste de envelhecimento acelerado $(1,59)$ e desempenho germinativo à altas temperaturas de $25-40^{\circ} \mathrm{C}$ na primeira contagem $(1,21)$, e germinação $(1,13)$.

A grande variabilidade genética para as características relacionadas às sementes de naboforrageiro é um reflexo da pequena importância que tem sido dada ao tema em programas de melhoramento vegetal, pois essa espécie somente vem sendo melhorada visando à redução do ciclo das plantas, altura e produtividade de grãos (SÁ, 2005). Em relação à seleção de genótipos, baseada em características relacionadas às sementes de naboforrageiro, como germinação e vigor, não foram encontrados relatos na literatura e os resultados obtidos na presente pesquisa evidenciaram melhorias quanto à qualidade fisiológica das sementes para as populações selecionadas.

Coeficientes de herdabilidade acima de $70 \%$ foram observados para os testes de germinação e classificação do vigor de plântulas a $20^{\circ} \mathrm{C}$, envelhecimento acelerado, germinação e primeira contagem a $25-40^{\circ} \mathrm{C}$, assim como emergência de plântulas em campo na primavera (Tabela 1). Isso permite predizer que o acréscimo na média das características selecionadas serão quase equivalentes ao diferencial de seleção imposto sobre aquele caráter (BUENO et al., 2006). Resultados igualmente promissores foram observados por VIEIRA et al. (2005) para peso e germinação de sementes de meiosirmãos de cenoura tipo Brasília.

Pelos dados da tabela 1, verificou-se que a germinação das sementes foi prejudicada em condições de temperaturas elevadas, pois o teste de germinação conduzido a $20^{\circ} \mathrm{C}$, recomendado pela RAS (BRASIL, 2009), proporcionou valores médios de germinação de $81 \%$, enquanto, nas temperaturas elevadas (20-35 e 25 $40^{\circ} \mathrm{C}$ ), a germinação foi de 53 e $21 \%$, respectivamente. A emergência de plântulas em campo na primavera também foi relativamente baixa $(55 \%)$, similar à germinação a $20-35^{\circ} \mathrm{C}$; esse desempenho das sementes do nabo-forrageiro confirma a necessidade de seleção genética das populações para a germinação em altas temperaturas para permitir a formação do campo com essa espécie em áreas tropicais.

As correlações genotípicas indicam que, ao selecionar um caráter, ocorrerão ganhos genéticos simultâneos nos outros correlacionados (BUENO et al., 2006). Assim, verificou-se (Tabela 2) que as populações de nabo-forrageiro com sementes de melhor desempenho na primeira contagem, germinação e envelhecimento acelerado podem ser selecionadas, visando ao melhor desempenho em altas temperaturas, pois, nestes testes, constatou-se alta 
Tabela 2 - Correlação genotípica e ambiental para os testes de avaliação $^{1}$ de sementes de 100 progênies de meioirmãos de nabo-forrageiro. Botucatu - SP, 2012.

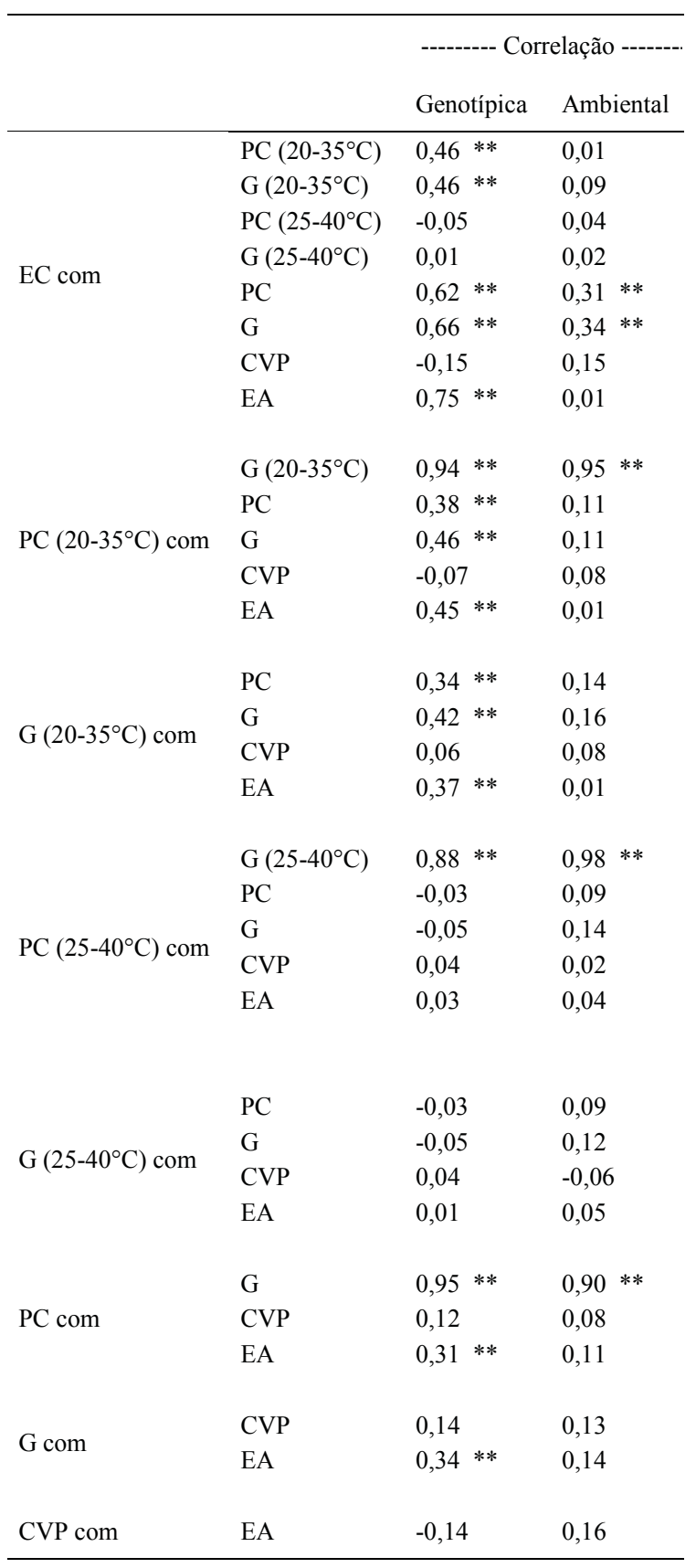

${ }^{1}$ Teste de emergência de plântulas na primavera (EC), primeira contagem (PC) e germinação $(\mathrm{G})$ em altas temperaturas (20-35 e $25-40^{\circ} \mathrm{C}$ ), primeira contagem, germinação e classificação do vigor de plântulas (CVP) a $20^{\circ} \mathrm{C}$ e envelhecimento acelerado (EA).

**Significativo ao nível de $1 \%$ de probabilidade pelo teste $\mathrm{F}$.

correlação genotípica com a germinação e primeira contagem (vigor) nas temperaturas de $20-35^{\circ} \mathrm{C}$ e emergência de plântulas em campo na primavera. No entanto, para os testes de primeira contagem e germinação a $25-40^{\circ} \mathrm{C}$, não houve correlações genotípicas positivas e significativas com nenhum dos demais testes de vigor avaliados.

Dessa forma, selecionar genótipos superiores com relação a um conjunto de características favoráveis de desempenho das sementes é de importância para novas cultivares a serem lançadas, pois disso depende o desempenho do lote no campo e armazenamento e, por conseguinte, a aceitação da cultivar pelo mercado agrícola (MARTINS et al., 2012).

As estimativas de ganho genético, as médias iniciais da população selecionada (20\%) e da média melhorada estão na tabela 3 e permitem estabelecer ganhos genéticos de seleção para todos os testes avaliados, embora menos expressivos para a primeira contagem e classificação do vigor de plântulas. Os menores ganhos genéticos estão associados a características com maior complexidade do controle gênico; assim, o teste de classificação do vigor de plântulas baseia-se no seu aspecto visual, ou seja, num caractere qualitativo e esses, de modo geral, têm menores ganhos genéticos que os quantitativos (BUENO et al., 2006).

O ganho genético obtido para a emergência de plântulas em campo na primavera e desempenho germinativo em altas temperaturas de 20-35 e 25$40^{\circ} \mathrm{C}$ (primeira contagem e germinação) foi elevado.

Tabela 3 - Estimativa de ganhos genéticos médios por seleção (GS) e em porcentagem (\%) e médias da população ${ }^{1}$ para os testes de qualidade ${ }^{2}$ de sementes avaliados em 100 progênies de meio-irmãos de nabo-forrageiro. Botucatu - SP, 2012.

\begin{tabular}{|c|c|c|c|c|c|}
\hline \multirow[b]{2}{*}{ Testes } & \multicolumn{2}{|c|}{--Ganho genético-- } & \multicolumn{3}{|c|}{----------- Médias ----------- } \\
\hline & GS & $\%$ & $\mu \mathrm{i}$ & $\mu \mathrm{s}$ & $\mu \mathrm{m}$ \\
\hline $\mathrm{PC}$ & 3,14 & 3,34 & 94,06 & 98,70 & 97,20 \\
\hline G & 16,49 & 20,34 & 81,09 & 99,38 & 97,58 \\
\hline CVP & 7,78 & 16,20 & 48,03 & 59,00 & 55,81 \\
\hline EA & 27,57 & 77,41 & 35,62 & 65,90 & 63,19 \\
\hline $\mathrm{PC}\left(20-35^{\circ} \mathrm{C}\right)$ & 11,51 & 24,97 & 46,11 & 62,90 & 57,62 \\
\hline $\mathrm{G}\left(20-35^{\circ} \mathrm{C}\right)$ & 14,51 & 27,43 & 52,88 & 67,38 & 67,39 \\
\hline $\mathrm{PC}\left(25-40^{\circ} \mathrm{C}\right)$ & 13,23 & 69,23 & 19,11 & 34,63 & 32,34 \\
\hline $\mathrm{G}\left(25-40^{\circ} \mathrm{C}\right)$ & 13,45 & 64,85 & 20,74 & 36,83 & 34,19 \\
\hline $\mathrm{EC}$ & 12,40 & 22,49 & 55,13 & 68,70 & 67,53 \\
\hline
\end{tabular}

${ }^{1}$ Médias iniciais da população ( $\mu$ i), de $20 \%$ da população selecionada $(\mu \mathrm{s})$, e média melhorada $(\mu \mathrm{m})$.

${ }^{2}$ Teste de primeira contagem $(\mathrm{PC})$, germinação $(\mathrm{G})$, classificação do vigor de plântulas (CVP), envelhecimento acelerado (EA), teste da primeira germinação e contagem em altas temperaturas (20-35 e $\left.25-40^{\circ} \mathrm{C}\right)$ e emergência de plântulas na primavera (EC). 
Entretanto, os valores em porcentagem para a seleção na temperatura de $20-35^{\circ} \mathrm{C}$ foi menor que o obtido a 25 $40^{\circ} \mathrm{C}$, pois, para a primeira condição de temperatura, a primeira contagem e germinação tiveram ganhos por seleção de 25 e $27 \%$, respectivamente, enquanto o segundo regime de temperatura resultou em valores de 69 e $65 \%$.

No entanto, estes ganhos genéticos relatados para $25-40^{\circ} \mathrm{C}$ não foram revertidos em maiores médias na seleção das 20 melhores progênies ( $\mu \mathrm{s})$ ou médias melhoradas $(\mu \mathrm{m})$, pois este regime de temperatura foi prejudicial ao processo germinativo, resultando nas menores médias de primeira contagem e germinação, com valores de 19 e $21 \%$, respectivamente (Tabela 3 ).

Quanto à média da população inicial durante a emergência de plântulas em campo na primavera, esta foi de $55 \%$ e, após a seleção, a estimativa da média melhorada elevou-se para $67 \%$. Isso aconteceu devido à escolha de progênies mais adaptadas às condições de temperaturas mais elevadas. Assim, a continuidade deste programa de melhoramento genético possibilitará a expansão da cultura do nabo-forrageiro para áreas com temperaturas mais elevadas na época de semeadura da cultura, como, por exemplo, a região Centro-oeste, Norte e Nordeste do país.

\section{CONCLUSÃO}

Os testes de germinação e vigor (primeira contagem, envelhecimento acelerado, primeira contagem e germinação em alta temperatura de 20$35^{\circ} \mathrm{C}$ ) são recomendados para selecionar populações de nabo-forrageiro adaptadas à germinação em condições de alta temperatura no campo.

\section{REFERÊNCIAS}

BRASIL. Ministério da Agricultura, Pecuária e Abastecimento. Regras para análise de sementes. Secretaria de Defesa Agropecuária. Brasília: MAPA/ACS, 2009. 395p.

BUENO, L.C.S. et al. Melhoramento genético de plantas: princípios e procedimentos. Lavras: UFLA, 2006. 319p.

CARVALHO, N.M.; NAKAGAWA, J. Sementes: ciência, tecnologia e produção. 5.ed. Jaboticabal: FUNEP, 2012. 590p.

CRUSCIOL, C.A.C. et al. Persistência de palhada e liberação de nutrientes do nabo-forrageiro no plantio direto. Pesquisa Agropecuária Brasileira, v.40, n.2, p.161-168, 2005. Disponível em: $<$ http://www.scielo.br/scielo.php?script=sci arttext\&pid $=$ S0100-204X2005000200009\&lng=pt\&nrm=is o\&tlng=pt $>$. Acesso em: 10 set. 2012. doi: 10.1590/S0100204X2005000200009.
CRUZ, C.D. Programa GENES: aplicativo computacional em genética e estatística. Viçosa: UFV, 2001. 648p. Disponível em: <www.ufv.br/dbg/genes/genes.htm>. Acesso em: 20 set. 2010.

DERPSCH, R.; CALEGARI, A. Plantas para adubação verde de inverno. Londrina: IAPAR, 1992. 80p. (Circular, 73).

KRZYZANOWSKI, F.C. Relationship between seed technology research and federal plant breeding programs. Scientia Agricola, v.55, n.esp, p.83-87, 1998.

MARCOS FILHO, J. Teste de envelhecimento acelerado. In: KRZYZANOWSKI, F.C. et al. (Ed.). Vigor de sementes: conceitos e testes. Londrina: ABRATES, 1999. Cap.3, p.1-24.

MARTINS, C.C. et al. Tests for the selection of carrot populations with greater vigor and longevity of seeds, Brasília, DF, 2012. In: INTERNATIONAL SYMPOSIUM ON SEED, TRANSPLANT AND STAND ESTABLISHMENT OF VEGETABLE CROPS, 6., 2012, Brasília, DF. Anais... Brasília: EMBRAPA hortaliças/ ISHS, 2012. V.1, 83p.

NAKAGAWA, J. Testes de vigor baseados no desempenho das plântulas. In: KRZYZANOWSKI, F.C. et al. Vigor de sementes: conceitos e testes. Londrina: ABRATES, 1999. p.2.1-2.24.

NERY, M.C. et al. Adequação do teste de germinação para sementes de nabo-forrageiro. Revista Brasileira de Sementes, v.31, n.2, p.177-187, 2009a. Disponível em: <http://www.scielo.br/ scielo.php?script=sci arttext\&pid=S0101-31222009000200021>. Acesso em: 27 set. 2012. doi: 10.1590/S0101-31222009000200021.

NERY, M.C. et al. Teste de vigor para avaliação da qualidade de sementes de nabo-forrageiro. Informativo Abrates, v.19, n.1, p.920 2009b. Disponível em: <http://www.abrates.org.br/portal/images/ stories/informativos/v19n1/artigo04.pdf>. Acesso em: 07 nov. 2012.

SÁ, R.O. Variabilidade genética entre progênies de meios irmãos de nabo-forrageiro (Raphanus sativus L. var. oleiferus) cultivar 'CATI AL 1000'. 2005. 39f. Tese (Doutorado em Agronomia/Agricultura) - Faculdade de Ciências Agronômicas, Universidade Estadual Paulista, Botucatu, SP.

SILVA, G.O. et al. Estratégias de seleção para germinação de sementes de cenoura em condições de temperaturas elevadas. Revista Ceres, v.58, n.1, p.121-125, 2011. Disponível em: <http://www.scielo.br/pdf/ rceres/v58n1/a18v58n1.pdf >. Acesso em: 04 out. 2011.

SOUZA, E.D. et al. Fitomassa e acúmulo de nitrogênio, em espécies vegetais de cobertura do solo para um Latossolo Vermelho distroférrico de Cerrado. Acta Scientiarum Agronomy, v.30, n.4, p.525-531, 2008. Disponível em: <http://periodicos.uem.br/ojs/ index.php/ActaSciAgron/article/view/5313/5313>. Acesso em: 08 out. 2012. doi: 10.4025/actasciagron.v3oi4.5313.

VALADARES, R.V. et al. Fertilidade do solo e produtividade de milho em sistema de adubação verde no norte de Minas. Planta Daninha, v.30, n.3, p.505-516, 2012. Disponível em: <http://www.scielo.br/ scielo.php?pid=S0100-83582012000300006\&script $=$ sci_arttext $>$. Acesso em: 07 nov. 2012. doi: 10.1590/S0100-83582012000300006.

VENCOVSKY, R.; BARRIGA, P. Genética biométrica no fitomelhoramento. Ribeirão Preto: Sociedade Brasileira de Genética, 1992. 496p.

VIEIRA, J.V. et al. Seleção de progênies de meio-irmãos de cenoura baseada em características de sementes. Horticultura Brasileira, v.23, p.44-47, 2005. Disponível em: <http://www. scielo.br/scielo.php?pid=s0102-05362005000100009\&script $=$ sci arttext>. Acesso em: 04 out. 2012. doi: 10.1590/S010205362005000100009 . 